\title{
Variability of Fatigue Crack Initiation Life in Flux Cored Arc Welded API 2W Gr.50 Steel Joints ${ }^{\dagger}$
}

\author{
Hye-Jeong Sohn ${ }^{1}$ and Seon-Jin Kim ${ }^{2 *}$ \\ ${ }^{1}$ Graduate Student, Department of Mechanical Design Engineering, Pukyong National University, Busan,Korea \\ ${ }^{2}$ Department of Mechanical and Automotive Engineering, Pukyong National University, Busan, Korea
}

(Manuscript Received June 8 2012; Revised July 31, 2012; Accepted August 25, 2012)

\begin{abstract}
Flux Cored Arc Welding (FCAW) is a common practice to join thick plates such as the structural members of large scale offshore structures and very large container ships. The objective of this study was to investigate the mechanical properties and variability of the fatigue crack initiation life in the flux cored arc welded API $2 \mathrm{~W}$ Gr.50 steel joints typically applied to offshore structures with a focus on the effect of the materials in fatigue crack growth life from the notch root of a compact tension specimen. Offshore structural steel (API $2 \mathrm{~W}$ Gr.50) plates (60-mm thick) were used to fabricate multi-path flux core arc welded butt welded joints to clearly consider fatigue fractures at the weld zone from the notch. Fatigue tests were performed under a constant amplitude cyclic loading of $\mathrm{R}=0.4$. The mean fatigue crack initiation life of the HAZ specimen was the highest among the base metal (BM), weld metal (WM), and heat affected zone (HAZ). In addition, the coefficient of variation was the highest in the WMl specimen. The variability of the short fatigue crack growth rates from the notch tips in the WM and HAZ specimens was higher than in BM.
\end{abstract}

Keywords: Flux Core Arc Welding, Fatigue Crack Initiation Life, Mechanical Property, Hardness Distribution, Variability

\section{Introduction}

API $2 \mathrm{~W}$ Gr.50 steel plate was originally designed for use in the production of offshore fixed and floating production platforms, where strength and material integrity is required in several dimensions. It is regulated by the American Petroleum Institute and in some cases certified by ABS (American Bureau of Shipbuilding). Because of its stringent restrictions, API has also been adopted in many other applications such as the base rings/cylinders for crane production, pilings for severe applications in bridge construction, and "fracture critical" applications in areas where resistance to vibration and torque is necessary [1].

\footnotetext{
† This paper was modified from an abstract submitted for presentation to a fall conference of KSOE, 28, October, 2011, Mokpo

${ }^{*}$ Corresponding author. Tel.: +82-51-629-6163, Fax.: +82-51-629-6150,

E-mail address: sjkim@pknu.ac.kr

Copyright $(\mathcal{C}$ KSOE 2012.
}

These thick plates are used for the production of TLP, FPSO, and SPAR, as shown in Fig. 1 [2].

Offshore structures and large container ships receive repeated loads in their environments, and these structures generally consist of a large number of welded components. Multi-pass welding is generally used in the assembly of ultra-thick plates. All of the classification societies demand failure design guidelines for this weld zone such as for the fatigue strength and CTOD. Many welding processes are sued for offshore structural steels. Of these, fluxcored arc welding (FCAW) is one of the most commonly used methods. FCAW or FCA is a semiautomatic or automatic arc welding process. This process is widely used in the offshore and ship building industries because of its high welding speed and portability. 


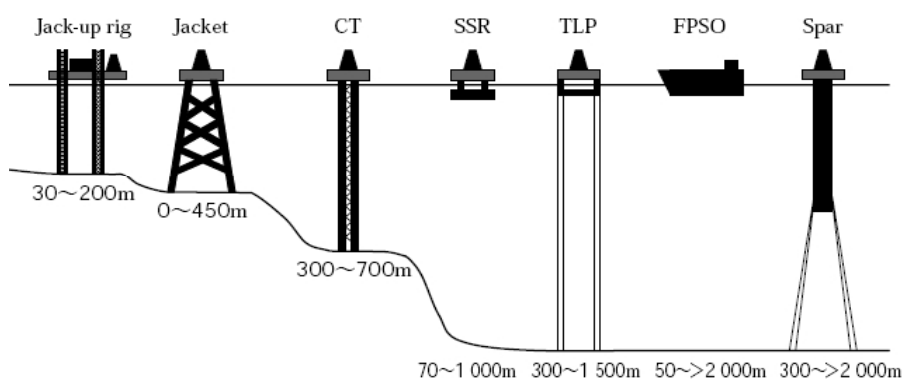

Fig. 1 Types of offshore structures and their working water depths.

Generally, the welded joint consists of three zones from the material's microstructural viewpoint: the weld metal (WM), heat affected zone (HAZ), and base metal (WM). These individual zones exhibit different mechanical behaviors such as hardness, along with different fatigue properties. Several studies have shown that no significant variations exist in the fatigue crack properties of these three zones. However, some studies showed that these three zones had significant differences in their fatigue crack propagation behaviors [3].

However, the process of fatigue crack initiation and/or fatigue crack growth is uncertain by nature, due to the variability of material properties, loading fluctuations, geometrical properties, and environmental conditions such as temperature and humidity [4].

For practical applications, it is important to understand the fatigue crack initiation and propagation behavior of cracked welded structures. Although the fatigue crack growth rate data of welded structures should be accurately determined and made available, very few data are available for welded structures from the stress range viewpoint. Howev$\mathrm{er}$, it is widely recognized that fatigue crack initiation and propagation are fundamentally probabilistic phenomena [5-10]. Risk assessment and remaining fatigue crack growth life prediction require accurate probabilistic fatigue crack growth models. It is essential that the procedures are reliable and sufficiently conservative.

The objective of this study was to investigate the mechanical properties and variability of fatigue crack initiation life for the FCAWed API 2W Gr.50 steel weldments typically applied for offshore structures. In order to clearly investigate the variability of the fatigue crack initiation life of materials in the three different zones, the weld metal (WM), heat affected zone (HAZ), and base metal (BM), exper- imental fatigue crack initiation tests for each of four specimens were performed on compact tension (CT) specimens under constant amplitude cyclic loading.

\section{Experimental Procedure}

Flux cored arc welding (FCAW or FCA) is a semi-automatic or automatic arc welding process. FCAW requires a continuously fed consumable tubular electrode containing a flux and a constantvoltage or, less commonly, a constant welding power supply. The process is widely used in construction because of its high welding speed and portability.

The flux cored arc welding process used in the experiment was a semi-automated process. The welding was carried out on $895 \times 125 \times 60 \mathrm{~mm}$ steel plates (API $2 \mathrm{~W}$ Gr.50). Table 1 shows the chemical composition of the parent material. The welding of these steel plates was performed by controlling the welding parameters, as given in Table 2. Multi-path welding was performed, conforming to ASME Sec. IX Code. Fig. 2 and Fig. 3 show schematic diagrams of the FCAWed API2W Gr.50 steel plate and butt welded joint, respectively. The distribution of the hardness in the weld joint at the middle part is given in Fig. 4. As shown in Fig. 4, the hardness drops steeply from the weld metal to HAZ, then increases slightly to the base metal, because of microstructural changes in the welded joint.

API $2 \mathrm{~W}$ Gr. 50 steel was used as the parent material or base metal (BM), which is used mainly in the ship-building and offshore structure construction industries. The material was acquired as $60-\mathrm{mm}$ thick plates produced by the S company. The chemical composition is given in Table 1, as mentioned in the above Section. The mechanical properties is also shown in Table 3. Fig. 5 shows the optical microstructure of base metal API $2 \mathrm{~W}$ Gr.50 steel, consisting of ferrite, pearlite and bainite. 
Table 1 Chemical composition of parent material (API 2W Gr.50) (wt. \%).

\begin{tabular}{cccccccccc}
\hline \hline $\mathrm{C}$ & $\mathrm{Si}$ & $\mathrm{Mn}$ & $\mathrm{P}$ & $\mathrm{S}$ & $\mathrm{Ni}$ & $\mathrm{Cr}$ & $\mathrm{Mo}$ & $\mathrm{Nb}$ & $\mathrm{Ti}$ \\
\hline 0.08 & 0.027 & 1.44 & 0.011 & 0.001 & 0.01 & 0.02 & 0.01 & 0.018 & 0.019 \\
\hline
\end{tabular}

Table 2 Weld parameters used in experimental work.

\begin{tabular}{cccccc}
\hline \hline $\begin{array}{c}\text { Size of filler met- } \\
\text { al }(\mathrm{mm})\end{array}$ & $\begin{array}{c}\text { Current range } \\
(\mathrm{A})\end{array}$ & $\begin{array}{c}\text { Voltage range } \\
(\mathrm{V})\end{array}$ & $\begin{array}{c}\text { Type of cur- } \\
\text { rent/Polarity }\end{array}$ & $\begin{array}{c}\text { Travel speed } \\
(\mathrm{mm} / \mathrm{sec})\end{array}$ & $\begin{array}{c}\text { Heat input } \\
(\mathrm{KJ} / \mathrm{mm})\end{array}$ \\
\hline 1.3 & $200 \sim 235$ & $27 \sim 32$ & $\mathrm{DC} / \mathrm{EP}$ & $4.35 \sim 6.78$ & $0.76 \sim 1.34$ \\
\hline
\end{tabular}

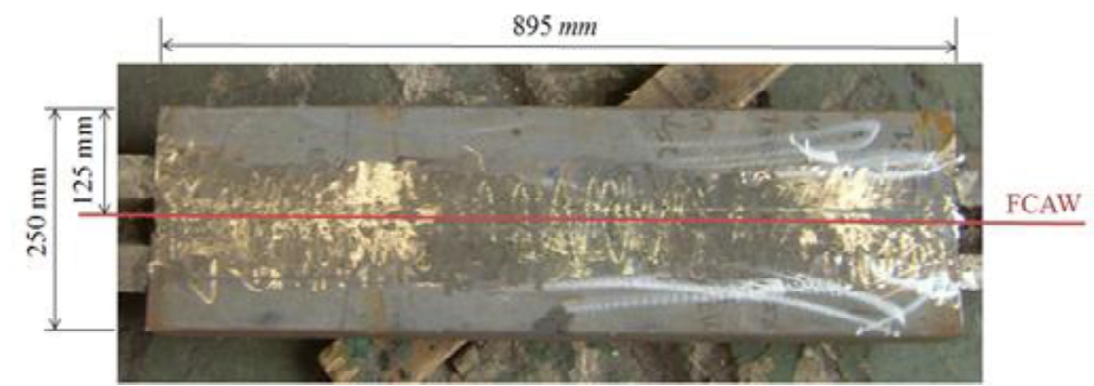

Fig. 2 Top view of FCA welded API 2W Gr.50 steel.

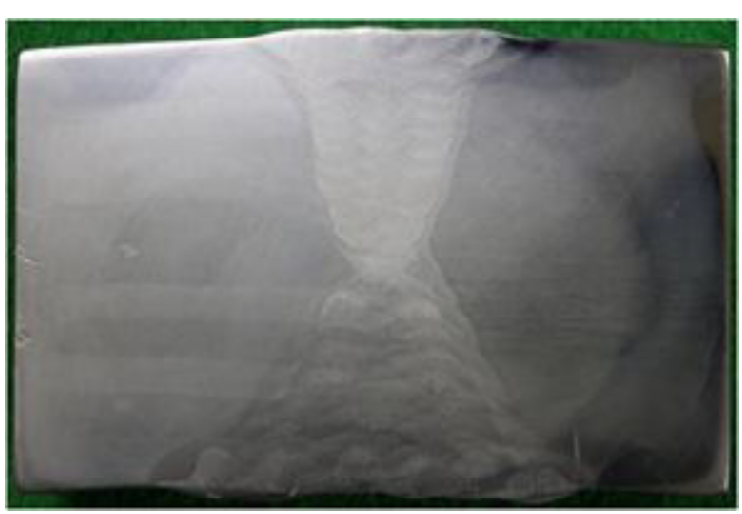

Fig. 3 Schematic diagram of FCA butt welded joint.

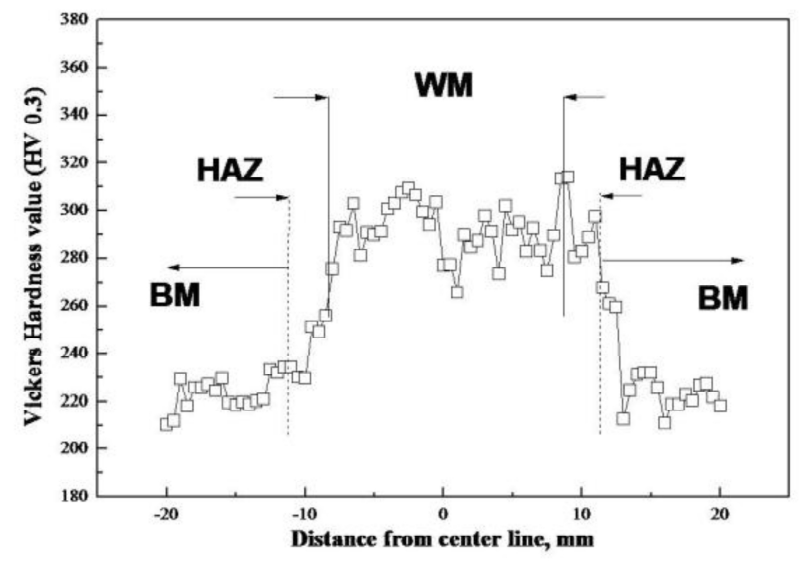

Fig. 4 Hardness distribution of FCA welded joint. 


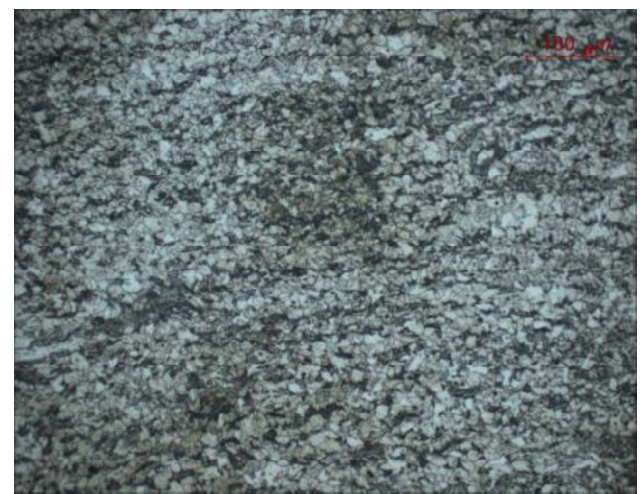

Fig. 5 Optical microstructure of base metal, API 2W Gr. 50 steel.

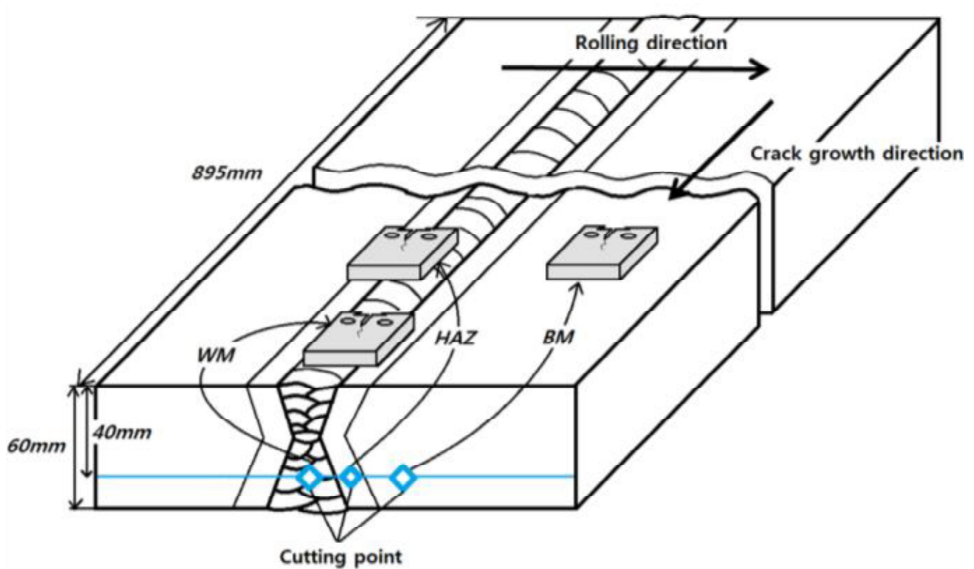

Fig. 6 Schematic diagram showing joint geometry and test specimens sectioned from FCA welded plate.
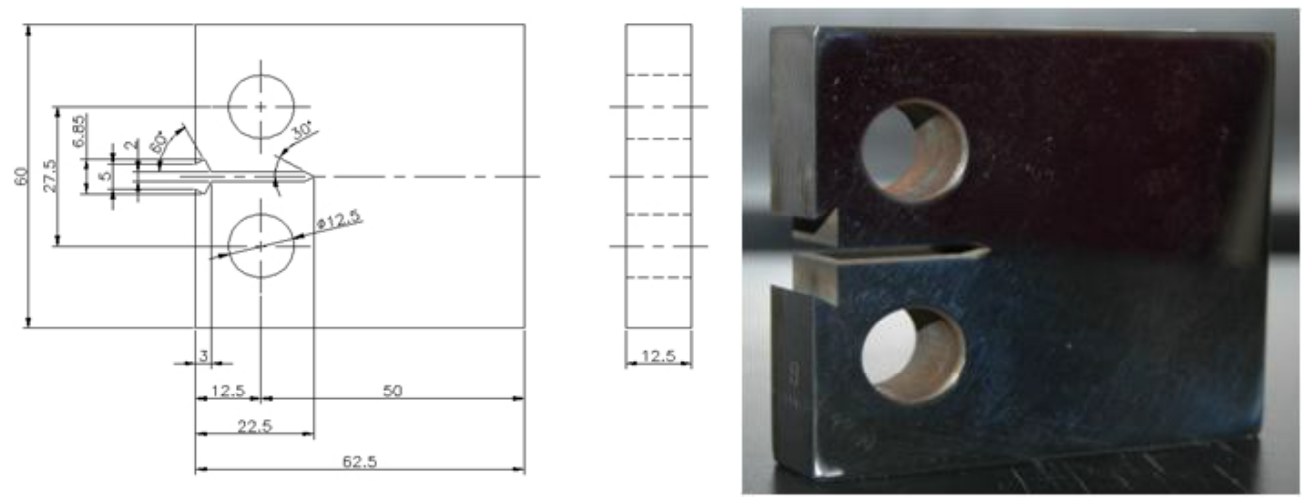

Fig. 7 Dimensions and photo of compact specimen used in this work.
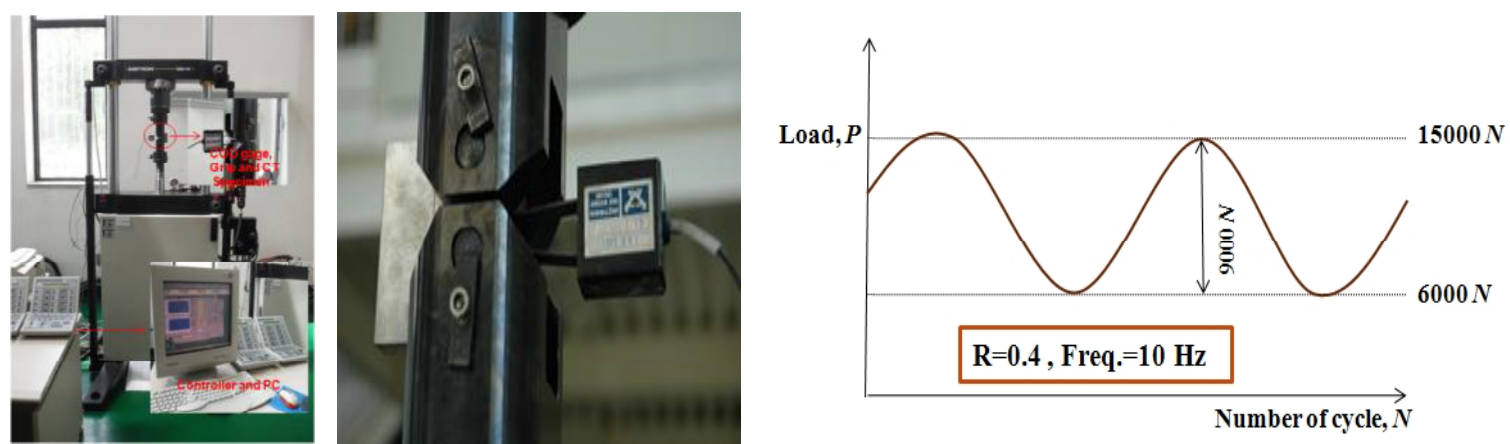

Fig. 8 Fatigue testing machine, large view of clevis grips, and load history used in this work. 
The dimensions of the joint geometry and various specimens sectioned from the FCA welded plate are shown in Fig. 6. As shown in Fig. 6, the fatigue crack initiation direction from the machine notch was aligned parallel to the welding direction. Tensile tests were conducted on circular solid bar specimens cut out parallel to the welding directions. Three specimens were tested for each location.

Fig. 7 illustrates the dimensions of the compact tension specimen used in this work. The specimens were cut out in the LT direction, as indicated in Fig. 6. An EDM notch was introduced for all specimens. In this study, in order to evaluate the effect of the variability of the fatigue crack initiation life on the material property, namely $\mathrm{WM}, \mathrm{HAZ}$, and BM, compact tension specimens were used for the constant amplitude loading fatigue tests. For these fatigue tests, a closed-loop servo-hydraulic mechanical machine (INSTRON 8821S) with a $100-\mathrm{kN}$ capacity was employed. Fig. 8 shows the fatigue testing machine and load history used in this work.

\section{Test Results and Discussion}

Fig. 9 shows the tensile fractured BM, WM, and HAZ specimens. The tensile test results are shown in Fig. 9. BM, WM, and HAZ had tensile strengths of 531, 634, and $561 \mathrm{MPa}$, respectively. The yield strengths were 447,601 , and $474 \mathrm{MPa}$, respectively. These results coincide well with the hardness results, which are shown in Fig. 4.

Fig. 10 shows the effect of the fatigue crack initiation life on the BM, WM and HAZ specimens. The mean initiation lives for $\mathrm{BM}, \mathrm{WM}$, and $\mathrm{HAZ}$ were $172,830,181,128$, and 257,500 cycles, respectively.
It is interesting to note that the resistance of the fatigue crack initiation life of HAZ was better than those of BM and WM. The statistical properties of the fatigue crack initiation life are also summarized in Table 4. As shown in these results, there is variability in the fatigue crack initiation life. Many studies on the statistical treatment of fatigue life and crack length have been performed, and these suggest that the Weibull distribution or log-normal distribution is a suitable way to analyze such fatigue data [11]. In this study, the scatter characteristics of the fatigue crack initiation life for FCA welded API $2 \mathrm{~W}$ Gr.50 steel were evaluated by using a 2-parameter Weibull distribution for the sake of convenience. The cumulative distribution function and density function are presented in the following equation.

$F(t, \alpha, \beta)=1-\exp \left[-\left(\frac{t}{\beta}\right)^{\alpha}\right]$

$f(t, \alpha, \beta)=\frac{\alpha}{\beta}\left\{\left(\frac{t}{\beta}\right)^{\alpha-1}\right\} \exp \left\{-\left(\frac{t}{\beta}\right)^{\alpha}\right\}$

In this equation, $t$ is the fatigue crack initiation life as a random variable, $\alpha$ is a shape parameter that presents the shape of the distribution, and $\beta$ is a scale parameter that presents the special life. In these equations, shape parameter $\alpha$ indicates not only the shape of the probability density function but also the failure mode and variability.

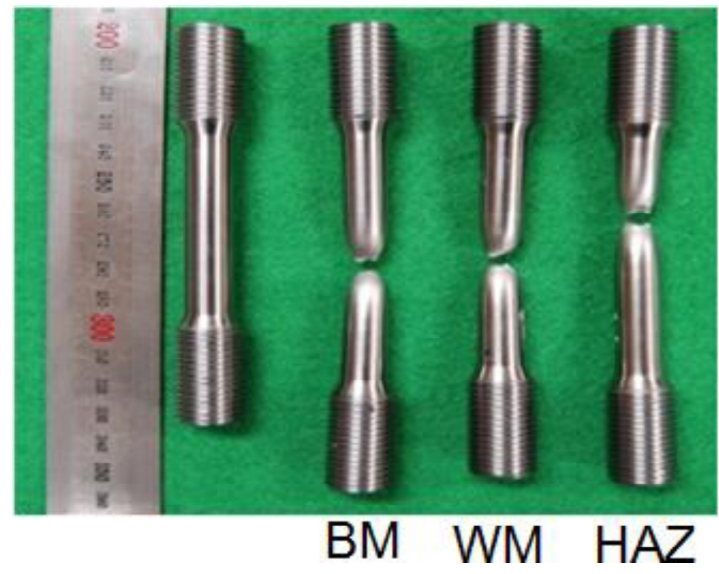

Fig. 8 Tensile fractured BM, WM, and HAZ specimens. 


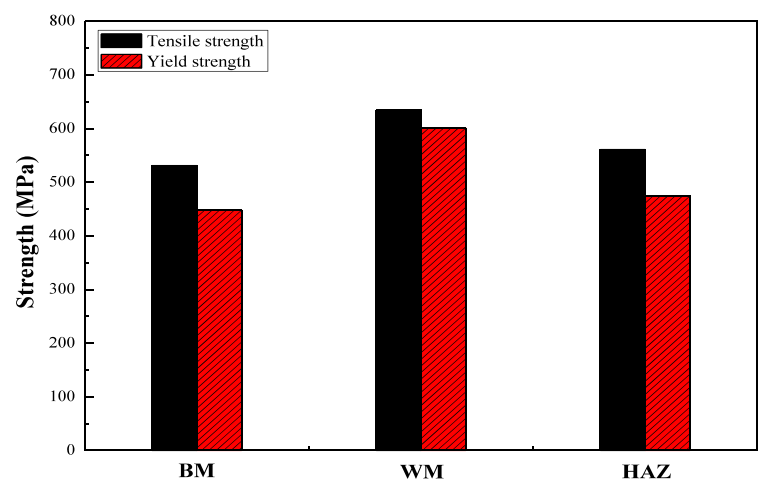

Fig. 9 Tensile test results for BM, WM. and HAZ.

Weibull plots of the fatigue crack initiation lives for BM, WM, and HAZ are shown in Fig. 11. The Weibull distribution holds for BM, WM and HAZ. The Weibull plots were also effective at presenting the distribution characteristics of the fatigue crack initiation life. The results of the Weibull analyses of the fatigue crack initiation lives are summarized in Table 5. These indicate that the variation in the material property strongly affected the shape parameter of the Weibull distribution in a fatigue crack initiation life. Particularly, the shape parameter of the WM specimen showed the smallest value in the BM, WM, and HAZ specimens. As shown in
Fig. 12, the effect of the refined microstructure formed in the weld zone was thought to play a dominant role in the variability of the fatigue crack initiation life and the statistical nature of the fatigue crack initiation. Fig. 13 shows a schematic diagram of the fatigue crack initiation from the notch to a length of $1.5 \mathrm{~mm}$ in the WM specimen. It was observed that the WM specimen exhibited crack branching compared to BM and HAZ. Thus, the results showed that the variability in the fatigue crack initiation life was sensitive to inhomogeneous micro-structural features, as well as the crack branching.

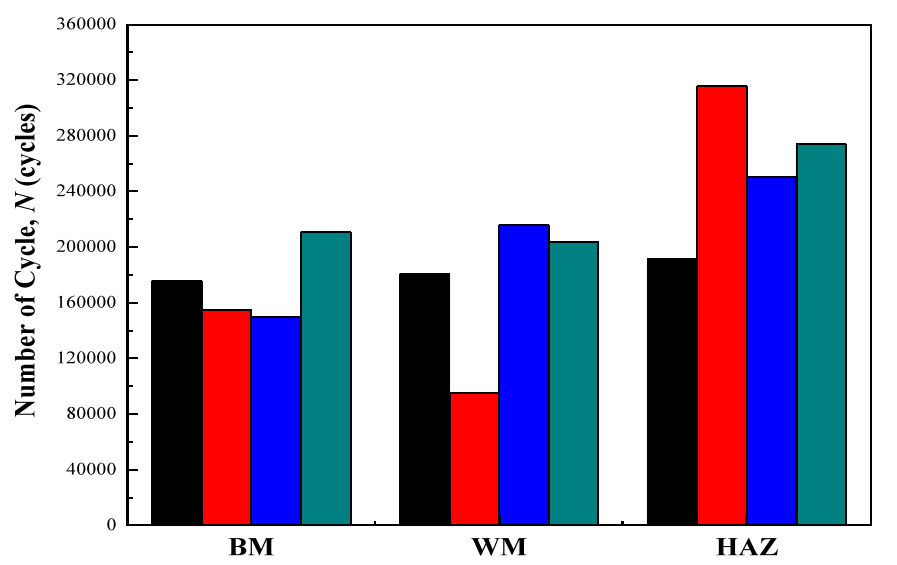

Fig. 10 Effect of fatigue crack initiation life on BM, WM and HAZ, specimens

Table 4 Statistical properties of fatigue crack initiation life.

\begin{tabular}{cccc}
\hline \hline & BM & WM & HAZ \\
\hline mean & 172830 & 181128 & 257500 \\
\hline variance & 27836 & 40187 & 51823 \\
\hline COV & 0.16 & 0.22 & 0.20 \\
\hline
\end{tabular}




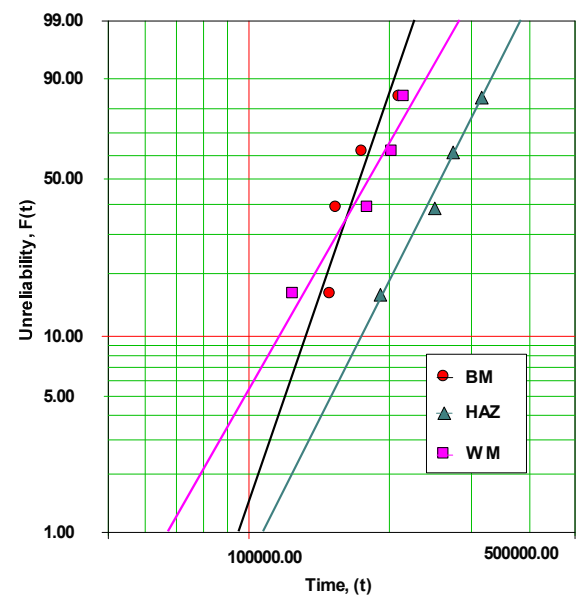

Fig. 11 Weibull plots of fatigue crack initiation lives for BM, WM, and HAZ.

Table 4 Weibull parameters for fatigue crack initiation life.

\begin{tabular}{cccc}
\hline \hline & BM & WM & HAZ \\
\hline shape parameter $(\alpha)$ & 7.08 & 4.27 & 4.81 \\
\hline scale parameter $(\beta)$ & 182830 & 198230 & 279830 \\
\hline$\rho($ RRX) & 0.9138 & 0.9655 & 0.9931 \\
\hline
\end{tabular}
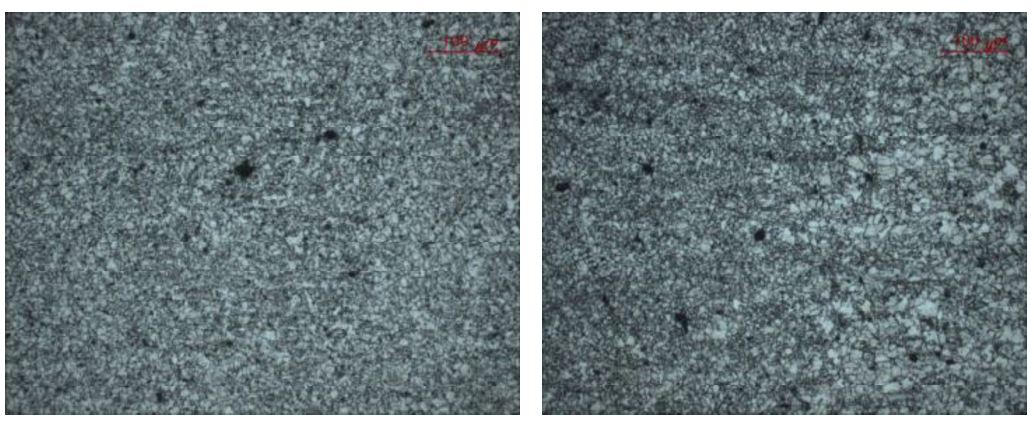

Fig. 12 Optical microstructures for WM and HAZ-to-BM.

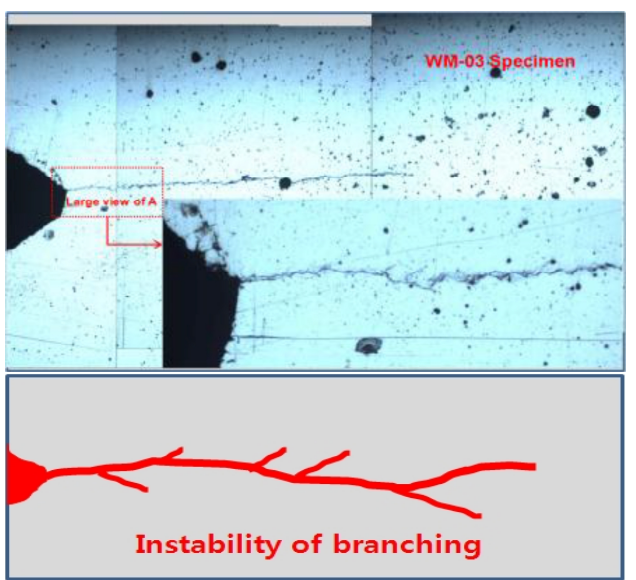

Fig. 13 Schematic diagram of fatigue crack initiation from notch for WM specimen. 
In order to evaluate the effect of the variability in the fatigue crack rate on $\mathrm{BM}, \mathrm{WM}$, and HAZ, the relationships between the fatigue crack growth rate and stress intensity factor range for $\mathrm{BM}, \mathrm{WM}$, and HAZ specimens are shown in Fig. 14. The short fatigue crack growth presented in this work was investigated from a machine notch to a length of 1.5 $\mathrm{mm}$. The short cracks were classified as mechanically short fatigue crack growth behavior [12]. The variability in the short fatigue crack growth rate decreased with an increase in the stress intensity factor range. The variability in the short fatigue crack growth rates for WM and HAZ was higher than that of BM. This results coincide well with the results for the fatigue crack initiation life. Once a crack is nucleated from the notch, it grows in the manner of a small or short crack, which is known to exhibit anomalous crack growth behavior [13-14]. As shown in Fig. 15, the crack growth behavior can be roughly expressed by the anomalous crack growth curves and the stable crack growth. At low stress ranges, the short crack growth rate shows three different behaviors: types $\mathrm{A}, \mathrm{B}$, and $\mathrm{C}$, as shown in Fig. 15. In a comparison with our experimental data, it seems that the fatigue crack growth rate follows type B of Fig. 14, which shows the plastic and elastic field's fatigue crack growth behavior. However, the reasons for this are not yet clear.
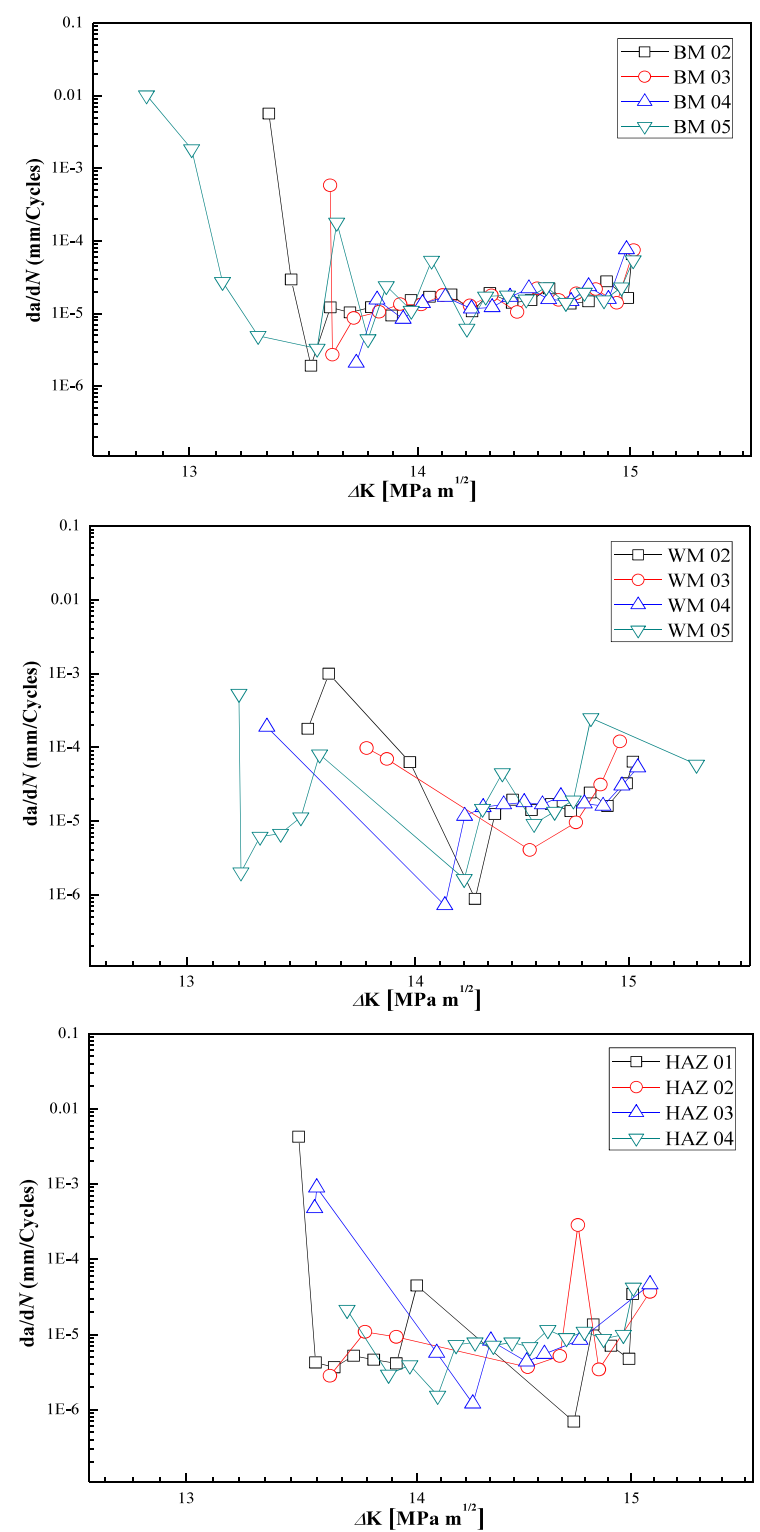

Fig. 14 Fatigue crack growth rate, da/dN vs. stress intensity factor range, $\Delta \mathrm{K}$. 

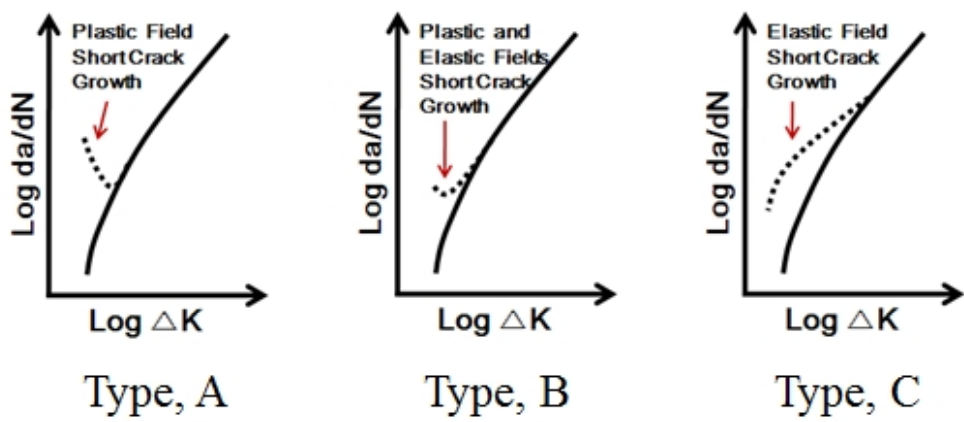

Fig. 15 Three different types of crack growth behaviors.

\section{Conclusions}

In this study, an experiment was carried out to investigate the mechanical properties and variability of the fatigue crack initiation life from a CT specimen notch for the FCA welded API $2 \mathrm{~W}$ Gr.50 steel weldments typically applied to offshore structures. It was found that the tensile strength of the WM specimen was higher than those of BM and WM, and for the same experimental conditions, the variability in the fatigue crack initiation life for WM was higher than those of BM and WM. The fatigue crack initiation life from the notch was represented by a 2-parameter Weibull distribution. The values of the shape parameters in the Weibull distributions for WM and HAZ were found to be 4.27 and 4.81, respectively.

\section{References}

[1] http://www.chapelsteel.com/api-2h-grade$\underline{50 . h t m l}$

[2] Kazuyuki, S. and Takeshi, S. (2003). "Welding Consumables for Offshore Structures," Technical Paper of Kobe Steel, Vol. 53, No. 2, pp. 85-89.

[3] Lee, H.K., Kim, K.S. and Kim, C.M. (2000). "Fracture Resistance of a Steel Weld Joint under Fatigue Loading," Engineering Fracture Mechanics, Vol. 66, pp. 403-419.

[4] Riahi, H., Bressoltte, Ph. and Chateauneuf, A. (2010). "Random Fatigue Crack Growth in Mixed Mode by Stochastic Collocation Method," Engineering Fracture Mechanics, Vol. 77, pp. 3292-3309.

[5] Min, L., Qing, S. and Yang, Q.X. (1996). "Large Sample Size Experimental Investigation on the Statistical Nature of Fatigue
Crack Initiation and Growth,” Int. J. Fatigue, Vol. 18, No. 2, pp. 87-94.

[6] Virkler, D.A., Hillberry, B.M. and Goal, P.K. (1979). "The Statistical Nature of Fatigue Crack Propagation," J. Engineering Materials and Technology, ASME, Vol. 101, pp. 148153.

[7] Ortiz, K, and Kiremidjian, A.S. (1986). "Time Series Analysis of Fatigue Crack Growth Rate Data," Engineering Fracture Mechanics, Vol. 25, No. 4, pp. 657-668.

[8] Itagaki, H., Ishizuka, D. and Huang, P. (1993). "Experimental Estimation of the Probability Distribution of Fatigue Crack Growth Lives," Probabilistic Engineering Mechanics, Vol. 8, No. 1, pp. 25-34.

[9] Wu, W.F. and Ni, C.C. (2007). "Statistical Aspects of Some Fatigue Crack Growth Data," Engineering Fracture Mechanics, Vol. 74, pp. 2951-2963.

[10]Lennart, B. and Ringsberg, J.W. (2009), “Assessment of Uncertainties in Life Prediction of Fatigue Crack Initiation and Propagation in Welded Rails," International Journal of Fatigue, Vol. 31, pp. 1413-1421.

[11]Goto, M. (19980. "Statistical Investigation of the Effect of Laboratory Air on the Fatigue Behavior of a Carbon Steel," Fatigue \& Fracture Engineering Materials \& Structures, Vol. 21, pp. 705-715.

[12]Costa, J.D., Brancot, C.M. and Radon, J.C. (1997). "Short Fatigue Crack Growth Behavior in Al 5083 Alloy," Int. J. Fatigue, Vol. 19, No. 2, pp. 161-168.

[13]Moltubakk, T., Thaulow, C. and Zhang, Z. (1999). "Application of Local Approach to Inhomogeneous Welds. Influence of Crack 
Position and Strength Mismatch," Engineering Fracture Mechanics, Vol. 62, pp. 445-462.

[14]Hou, C.Y. and Charng, J.J. (1997). "Models for the Estimation of Weldment Fatigue
Crack Initiation Life,” Int. J. Fatigue, Vol. 19, No. 7, pp. 537-541. 